\title{
A nationwide population-based study of the inflammatory bowel diseases between 1998 and 2008 in Taiwan
}

\author{
Shu-Chen Wei ${ }^{1}$, Meng-Hung Lin², Chien-Chih Tung ${ }^{1,3}$, Meng-Tzu Weng ${ }^{1,4}$, Jen-Shin Kuo ${ }^{1,5}$, Ming-Jium Shieh ${ }^{6}$, \\ Cheng-Yi Wang ${ }^{1}$, Wen-Chao Ho ${ }^{2}$, Jau-Min Wong ${ }^{1 *}$ and Pau-Chung Chen ${ }^{7,8,9^{*}}$
}

\begin{abstract}
Background: The incidence of the inflammatory bowel diseases (IBD), ulcerative colitis (UC) and Crohn's disease (CD), has been increasing in Asia. We probed the nationwide registered database to assess the incidence, prevalence, gender distribution, age of diagnosis and the survival status of IBD patients in Taiwan.

Methods: A retrospective study was conducted to analyze the registered database compiled by the National Health Insurance provided by the Department of Health, Taiwan, from January 1998 through December 2008.

Results: A total of 1591 IBD patients were registered from 1998 to 2008 in Taiwan (CD: 385; UC: 1206). The incidence of CD increased from 0.19/100,000 in 1998 to 0.24/100,000 in 2008. The incidence of UC increased from $0.61 / 100,000$ in 1998 to $0.94 / 100,000$ in 2008. The prevalence of CD increased from $0.19 / 100,000$ in 1998 to 1.78 / 100,000 in 2008. The prevalence of UC increased from $0.61 / 100,000$ in 1998 to $7.62 / 100,000$ in 2008. Male to female ratio for CD was 2.22 and 1.64 for UC. Age of registered for CD was predominantly between 20 to 39, and for UC between 30 to 49 years of age. The standardized mortality ratio (95\% Cl) was $4.97(3.72-6.63)$ for CD and 1.78 (1.46-2.17) for UC, from 1998 to 2008 in Taiwan.

Conclusions: Using the Taiwan nationwide database for IBD, the incidence and prevalence of IBD in Taiwan significantly increased from 1998 to 2008. The mortality rate was higher for CD patients than UC patients, and both were higher than the general population.
\end{abstract}

Keywords: Crohn's disease, Ulcerative colitis, Incidence, Prevalence, Taiwan, Nationwide

\section{Background}

The inflammatory bowel diseases (IBDs) Crohn's disease (CD) and ulcerative colitis (UC) are common causes of chronic gastrointestinal disease in the developed world. Initially regarded as a Western lifestyle disease, inflammatory bowel disease (IBD) is increasing in both incidence and prevalence in many parts of the Asia Pacific area [1-8]. The reason for this increasing trend has not been established but is most likely related to environment factors, including improved hygiene and "Westernization" of $\operatorname{diet}[9]$.

\footnotetext{
* Correspondence: jmwong@ntu.edu.tw; pchen@ntu.edu.tw 'Department of Internal Medicine, National Taiwan University Hospital and College of Medicine, 7 Chung Shan South Road, Taipei, Taiwan 7 Institute of Occupational Medicine and Industrial Hygiene, National Taiwan University College of Public Health, 17 XuZhou Road, Taipei, Taiwan
}

Based on a hospital (National Taiwan University Hospital)-based analysis, we previously showed that $\mathrm{CD}$ as well as UC has increased in both incidence and prevalence in Taiwan [10-12]. The National Taiwan University Hospital is a tertiary referral center in Taiwan; with the first case of ulcerative colitis being diagnosed in 1969. The previous reports offered a detailed disease phenotypic analysis with a long follow-up period (from 1989 to 2008). However, the exact condition of the general incidence and prevalence of $\mathrm{CD}$ and UC in Taiwan still needs a nationwide-based collection of data for a more representative and comprehensive analysis.

In Taiwan, the National Health Insurance provided by the Department of Health, Executive Yuan of Taiwan government was launched in 1995. Almost 99\% of the residents of Taiwan subscribe to this program for their 
health insurance. Since 1997, CD and UC, due to their potential for repetitive admissions and the need for chronic, careful caring, are registered as catastrophic illnesses. When a patient's ailment is diagnosed by a physician as a "catastrophic illness" under Department of Health guidelines, the patient can submit related information and apply for a catastrophic illness certificate/ registration. For IBD, the application includes the clinical diagnosis, pathological report as well as the possible image studies to be formally reviewed to validate and register the patient's diagnosis of $\mathrm{CD}$ or $\mathrm{UC}$, as well as for excluding intestinal tuberculosis. In this study, we used this nationwide-based data set to reveal the incidence, prevalence, age/gender distribution and the mortality rate of IBD patients in Taiwan.

\section{Methods}

Data source and ethical considerations

The nationwide population-based Taiwanese study of IBD was compiled between January 1998 and December 2008. Data was obtained from the Taiwan National Health Insurance (NHI) research database, which has been routinely collected by the National Health Research Institute (NHRI). These high quality databases have previously been used for epidemiologic research, information on prescription use, diagnoses, and hospitalizations [13-15]. With strict confidentiality guidelines being closely followed in accordance with personal electronic data protection regulations; the NHRI anonymized and maintained the NHI reimbursement data as files suitable for research. In addition, this study was approved by the Ethics Review Board at the National Taiwan University Hospital.

\section{Patient identification}

We used the diagnostic code (The International Classification of Diseases, Ninth Revision, Clinical Modification 2001 edition) to retrieve the IBD patients (UC: 556.XX; CD: 555.XX) from the catastrophic illness registration database. For each patient, medical records were collected in the NHI claim database, including date of admission, date of discharge, dates of visits, clinical diagnosis, prescription and total expenditure. The databases also contained patient information, including sex, date of birth and date of death.

\section{Statistical analyses}

The characteristics of IBD patients, including the year of diagnosis, sex ratio and age distribution, were described in this study. The annual incidence and prevalence were defined as the number of newly diagnosed patients and the number of patients with IBD per 100,000 persons per year, respectively, namely, the crude incidence and prevalence. We used the Kaplan-Meier method to estimate IBD cumulative survival rate over an eleven year follow-up period. To compare with the general population of Taiwan, the standardized mortality ratio and 95\% confidence interval were calculated based on the Poisson assumption. Furthermore, the direct mortality rate was also standardized to the WHO 2000 standard population using 5-year age groups per 1,000 person-years. All statistical analyses were performed with the SAS version 9.3 (SAS Institute, Cary, NC, USA). A $P$ value of less than 0.05 was set to declare statistical significance.

\section{Results}

A total of 1,591 IBD patients were registered from 1998 to 2008 in Taiwan. Among them, 385 were diagnosed with CD and 1,206 with UC. As shown in Figure 1, the incidence of CD increased from $0.19 / 100,000$ in 1998 to $0.24 / 100,000$ in 2008 . The incidence of UC increased from $0.61 / 100,000$ in 1998 to $0.94 / 100,000$ in 2008 . When this period was arbitrarily divided into the first stage as 1998 to 2003 and second stage from 2004 to 2008 , the mean incidence for $C D$ in the first stage was $0.16 / 100,000$ and $0.22 / 100,000$ for the second stage; the incidence of $C D$ increased significantly from the first stage to the second stage $(\mathrm{p}=0.005)$. For $\mathrm{UC}$, the mean incidence in the first stage was $0.70 / 100,000$ and 0.88 / 100,000 for the second stage; the incidence of UC increased also significantly from the first stage to the second stage $(\mathrm{p}=0.047)$.

As shown in Figure 2, the prevalence of $\mathrm{CD}$ increased from $0.19 / 100,000$ in 1998 to $1.78 / 100,000$ in 2008. The prevalence of UC increased from $0.62 / 100,000$ in 1998 to $7.62 / 100,000$ in 2008 . The mean prevalence for $C D$ in the first stage was $0.51 / 100,000$ and $1.42 / 100,000$ for the second stage; the prevalence of CD increased significantly from the first stage to the second stage $(\mathrm{p}=0.0003)$. For $\mathrm{UC}$, the mean prevalence in the first stage was 2.2/ 100,000 and $6.12 / 100,000$ for the second stage; the prevalence of $\mathrm{UC}$ increased also significantly from the first stage to the second stage $(\mathrm{p}=0.0005)$.

The year of diagnosis and sex-specific number of patients with CD and UC in Taiwan from 1998 to 2008 are

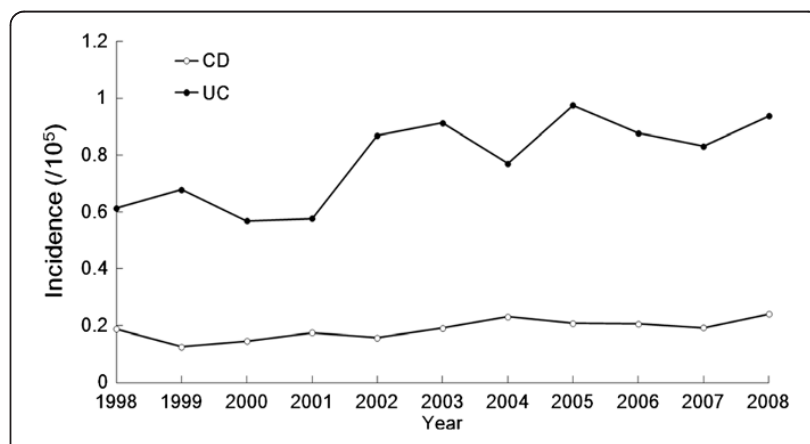

Figure 1 Incidence of IBD from 1998-2008 in Taiwan. 


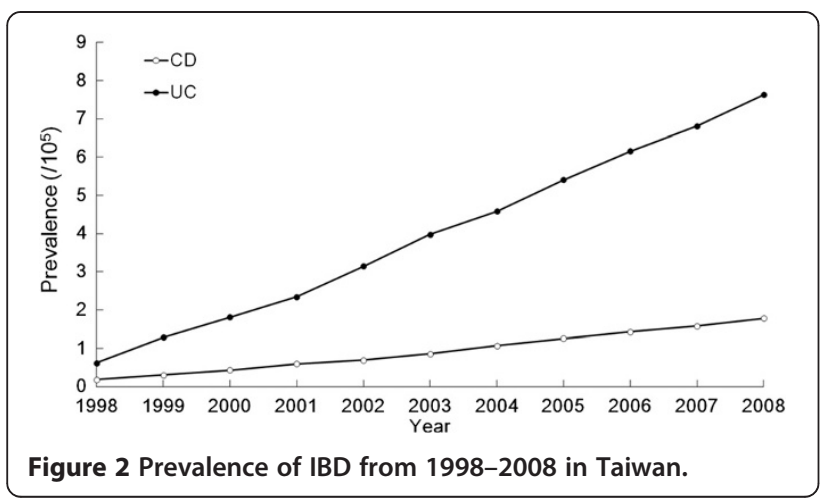

summarized in Table 1. Sex- and age-specific number of patients registered with $\mathrm{CD}$ are summarized in Table 2, and for UC in Table 3. The age of registration for CD patients was primarily between 20 to 39 (Figure 3), with the mean and standard deviation of 37.8 and 18.8 years of age, respectively. The age of registration for UC was mostly between 30 to 49 years old (Figure 4), with the mean and standard deviation of 44.5 and 15.8 years old,

Table 1 Year of diagnosis and sex-specific number of patients with Crohn's disease and ulcerative colitis in Taiwan, 1998-2008

\begin{tabular}{ccccc}
\hline Year of diagnosis & Male & Female & Total & Male to female ratio \\
\hline Crohn's disease & & & & \\
1998 & 25 & 13 & 38 & 1.9 \\
1999 & 18 & 10 & 28 & 1.8 \\
2000 & 22 & 10 & 32 & 2.2 \\
2001 & 28 & 12 & 40 & 2.3 \\
2002 & 27 & 9 & 36 & 3 \\
2003 & 26 & 17 & 43 & 1.5 \\
2004 & 37 & 15 & 52 & 2.5 \\
2005 & 33 & 15 & 48 & 2.2 \\
2006 & 32 & 16 & 48 & 2 \\
2007 & 31 & 14 & 45 & 2.2 \\
2008 & 41 & 15 & 56 & 2.7
\end{tabular}

\begin{tabular}{ccccc}
\hline Ulcerative colitis & & & & \\
1998 & 69 & 49 & 118 & 1.4 \\
1999 & 91 & 44 & 135 & 2.1 \\
2000 & 78 & 42 & 120 & 1.9 \\
2001 & 82 & 37 & 119 & 2.2 \\
2002 & 113 & 76 & 189 & 1.5 \\
2003 & 123 & 72 & 195 & 1.7 \\
2004 & 100 & 69 & 169 & 1.4 \\
2005 & 136 & 85 & 221 & 1.6 \\
2006 & 116 & 85 & 201 & 1.4 \\
2007 & 119 & 74 & 193 & 1.6 \\
2008 & 123 & 95 & 218 & 1.3 \\
\hline
\end{tabular}

Table 2 Sex- and age-specific number of patients registered as Crohn's disease in Taiwan, 1998-2008

\begin{tabular}{cccc}
\hline Age group & Male & Female & Total \\
\hline $0-9$ & 18 & 8 & 26 \\
$10-19$ & 30 & 16 & 46 \\
$20-29$ & 77 & 17 & 94 \\
$30-39$ & 72 & 30 & 102 \\
$40-49$ & 56 & 26 & 82 \\
$50-59$ & 26 & 23 & 49 \\
$60-69$ & 22 & 14 & 36 \\
$70-79$ & 18 & 7 & 25 \\
$\geq 80$ & 1 & 5 & 6 \\
\hline
\end{tabular}

respectively. Male to female ratios for $\mathrm{CD}$ was 2.22 and 1.64 for UC. These ratios reflect a male predominant pattern in Taiwan for CD over UC ( $\mathrm{p}=0.01)$ (Figure 5).

As shown in Figure 6, the survival status of $\mathrm{CD}$ patients after registration for one year, 5 years and 10 years were: $96 \%, 90 \%$ and $82 \%$, respectively. For UC patients, the survival status after registration for one year, 5 years and 10 years were: $99 \%, 95 \%$ and $90 \%$, respectively. There was a statistical difference between the survival status of UC and CD patients from 1998 to 2008 in Taiwan $(\mathrm{p}=0.001)$. The standardized mortality ratio (95\% CI) was 4.97 (3.72-6.63) and the standardized mortality rate (per 1,000 person-years) was 29.7 for CD; and the standardized mortality ratio $(95 \% \mathrm{CI})$ was 1.78 $(1.46-2.17)$ with the standardized mortality rate (per 1,000 person-years) of 9.62 for UC from 1998 to 2008 in Taiwan.

\section{Discussion}

Increased incidence and prevalence of IBD in Asia have been reported [1,3-12]. This information is mostly based on hospital-based data except for a report from Japan where there is a nationwide registration system [16]. By using a nationwide registration system in Taiwan,

Table 3 Sex- and age-specific number of patients registered as ulcerative colitis in Taiwan, 1998-2008

\begin{tabular}{cccc}
\hline Age group & Male & Female & Total \\
\hline $0-9$ & 8 & 3 & 11 \\
$10-19$ & 34 & 26 & 60 \\
$20-29$ & 175 & 76 & 251 \\
$30-39$ & 290 & 164 & 454 \\
$40-49$ & 264 & 162 & 426 \\
$50-59$ & 193 & 138 & 331 \\
$60-69$ & 109 & 92 & 201 \\
$70-79$ & 61 & 58 & 119 \\
$\geq 80$ & 16 & 9 & 25 \\
\hline
\end{tabular}




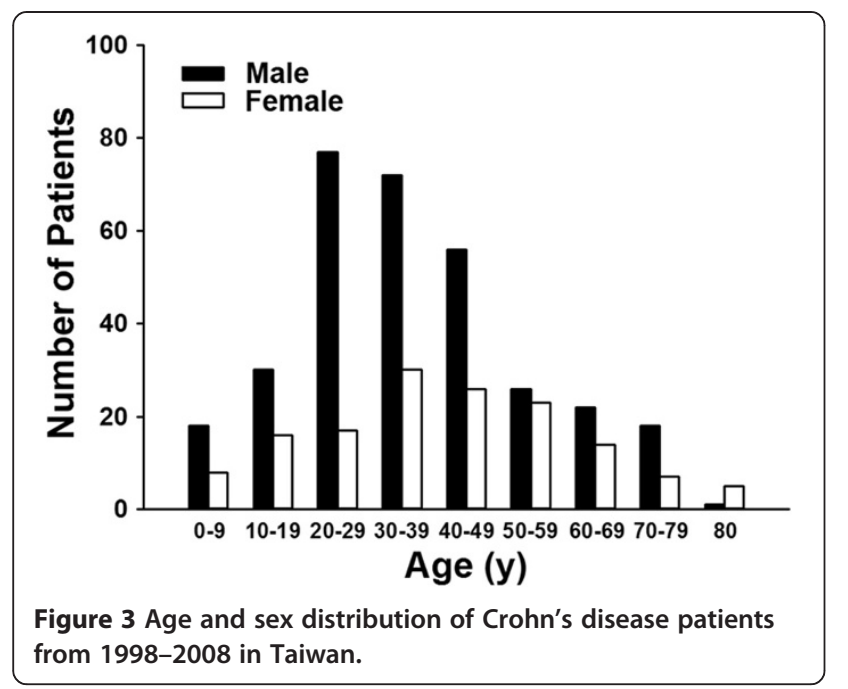

we confirmed this phenomenon by adding a second nationwide-based data analysis in Asia, which confirmed that the incidence and prevalence of IBD increased from 1998 to 2008 in Taiwan. From our experience, the true IBD patient number should be more than the registered number as there are always IBD patients who have not yet registered or who have not passed the registration process, therefore, there is no way to know the real number. The bottom line is that we have at least the number of cases reported in this study with a confirmed diagnosis of IBD and the number of cases increased significantly over the past years in Taiwan. Although the incidence (CD: 0.24/100,000; UC: 0.94/ 100,000 , in 2008) and prevalence (CD: 1.78/100,000; UC: $7.62 / 100,000$, in 2008) increased in Taiwan, they were still lower than the reports from Japan (prevalence: approximately 21/100,000 for CD and 63.6/100,000 for UC), Korea (prevalence: approximately $11 / 100,000$ for CD and

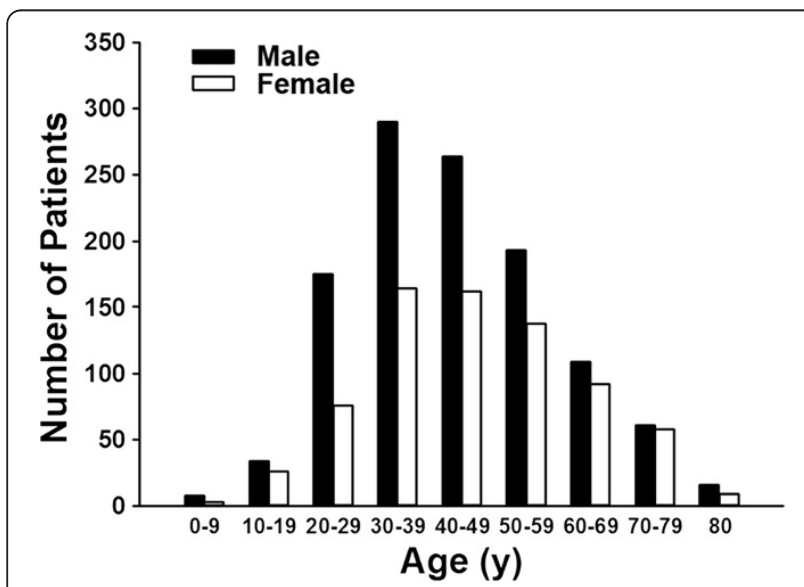

Figure 4 Age and sex distribution of ulcerative colitis patients from 1998-2008 in Taiwan.

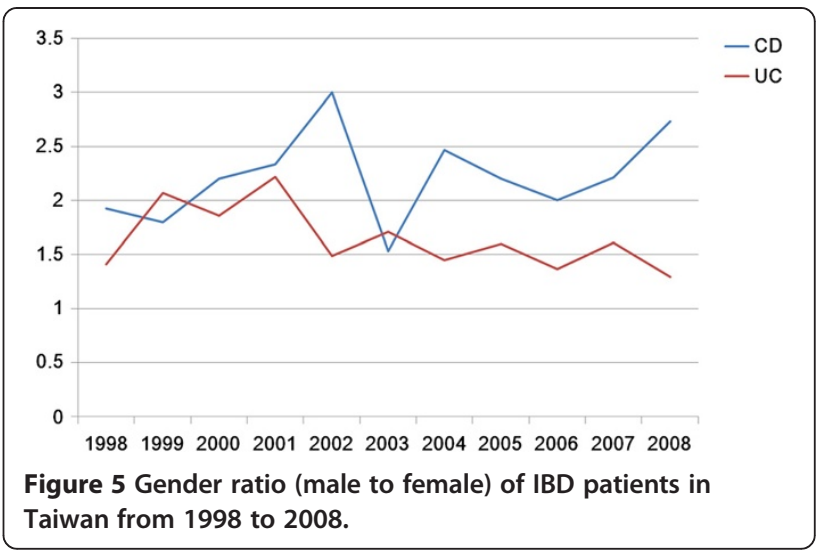

30.9/100,000 for UC), and much lower than those from Western Countries (prevalence: approximately 200/ 100,000 for CD and 400/100,000 for UC) $[1,9,16]$. And according to the recently pusblised large scale populationbased epidemiologic study across nine countries in AsiaPacific showing geographic variability in disease incidence even within Asia [17]. Taiwan appeared to have disease incidence that is lower than Hong Kong, some parts of mainland China, and Macau, and relatively similar to that of Malaysia and Sri Lanka, but higher than those of Thailand and Indonesia. One may speculate that different degrees of urbanization/socioeconomic status may play a part in the variation.

The mean age of patients registered with $\mathrm{CD}$ was 37.8 and for UC was 44.5 years of age. We previously have shown that, based on a referral center in Taiwan, the mean age of diagnosis for $\mathrm{CD}$ was 30.5 and for UC was 36 in the National Taiwan University Hospital [11,12]. This difference might be related to the lag between diagnosis and registration, as well as the possible gap between the IBD diagnosis efficiency between an experienced center and the other general hospitals. Nonetheless, the mean age for $\mathrm{CD}$ and $\mathrm{UC}$ registered patients was still within the range reported from other countries in Asia [16].

Considering the male to female ratio, in the current study we found the ratio for $\mathrm{CD}$ was 2.22 and for $\mathrm{UC}$ was 1.64, which was consistent with our previous results which showed 1.82 for $\mathrm{CD}$ and 1.35 for UC [11,12]. Both diseases showed a male predominant pattern, especially significant for $\mathrm{CD}$. This observation was consistent with the reports from the other Asian countries, most of them revealed a male predominant prevalence. Interestingly, this differed from reports from Western countries $[16,18]$.

The survival status, or vice versa, the mortality rate from this report was quite different from previous reports, even when compared to our previous results based on a referral center follow-up study which showed the accumulated mortality rate for $\mathrm{CD}$ to be $2.7 \%$ (3 of 110 ) and $1.72 \%$ for UC (7 of 406) from 1988 to 2008. In 


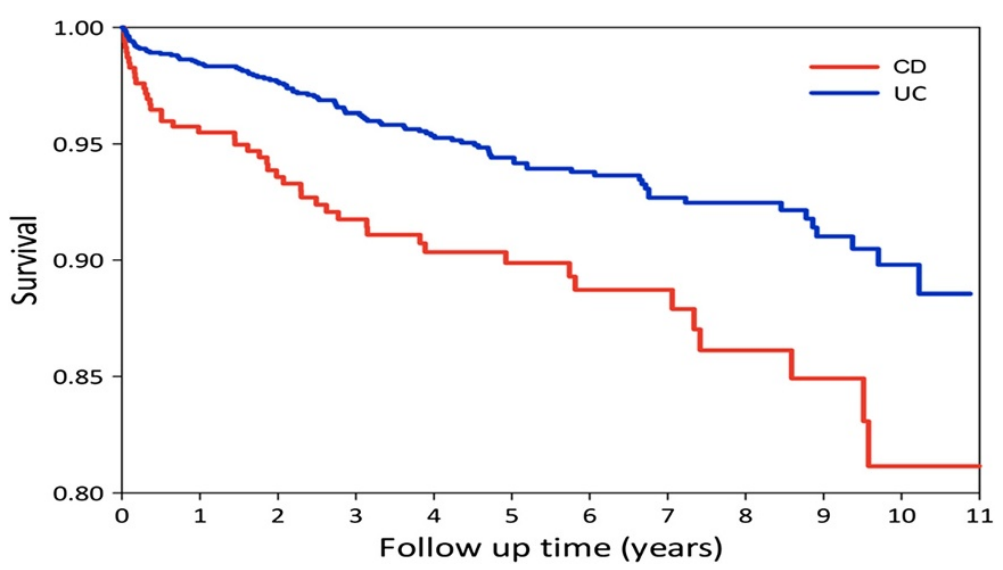

Figure 6 Survival rate of IBD patients in Taiwan from 1998 to 2008.

this study, the survival rate of $\mathrm{CD}$ patients after the registration for one year, 5 years and 10 years were: $96 \%$, $90 \%$ and $82 \%$, respectively. For UC patients, the survival status after the registration for one year, 5 years and 10 years were: $99 \%, 95 \%$ and $90 \%$, respectively. There was a statistical difference of the survival status between UC and CD patients from 1998 to 2008 in Taiwan ( $\mathrm{p}=$ 0.001). When compared with the general population, the standardized mortality ratio $(95 \% \mathrm{CI})$ was $4.97(3.72-$ 6.63) and the standardized mortality rate (per 1,000 person-years) was 29.7 for $\mathrm{CD}$; the standardized mortality ratio $(95 \% \mathrm{CI})$ was $1.78(1.46-2.17)$ with the standardized mortality rate (per 1,000 person-years) as 9.62 for UC from 1998 to 2008 in Taiwan. Both were higher than the reports from Japan as well as from most Western countries, with the standardized mortality ratio for $\mathrm{CD}$ around 1.5 fold the general population. The mortality rate of $C D$ patients was slightly higher than the general population and the mortality rates for UC patients, either from Japan or from Western countries were mostly the same as the general population [19-31].

The higher mortality shown in this study was unexpected. However, as the data was anonymized, only the date of death but not the cause of death nor comorbidity could be traced from this data set. The registered data only provided the diagnosis, no phenotypic information was included. Therefore, we were not able to know whether the higher mortality resulted from the severity of the disease or not. The ages of diagnosis in this cohort were comparable to the reports from other Asian countries $[1,17,30]$, age did not seem to be able to explain the higher mortality. However, when comparing the results from a referral center (National Taiwan University Hospital, for example) with the nationwide population-base, patients tended to be diagnosed at earlier ages and with less mortality when seen in a referral center. This result might reflect the low awareness of IBD in the general practice, since previously in Taiwan, IBD was a relatively low prevalence disease. Experience diagnosing and treating IBD patients when they presented outside the referral center (NTUH, for example) was lagging. Therefore, since 2010, we have started to emphasize the increasing trend of IBD as well as an IBD awareness education program. Hopefully in the future, we can improve the awareness, the quality of care, and the outcome of IBD patients in Taiwan. Our experience might also afford other countries where IBD is low in prevalence, to modify their quality of care in treating IBD patients which should translate into improving the prognosis of IBD patients.

\section{Conclusion}

Using the Taiwan nationwide database for IBD, the incidence and prevalence of IBD in Taiwan significantly increased from 1998 to 2008.

The mortality rate was higher for $\mathrm{CD}$ patients than UC patients, and both were higher than the general population. After our promotion of the disease awareness, we hope the outcome of IBD patients in Taiwan could be improved in the future.

\section{Competing interests}

The authors declare that they have no competing interests.

\section{Authors' contributions}

SCW, CCT, MTW, JSK, MJS, CYW, JMW: study desing, data collection, manuscript preparation. MHL, WCH, PCC: statistics analysis and manucript preparation. All authors read and approved the final manuscript.

\section{Author details}

'Department of Internal Medicine, National Taiwan University Hospital and College of Medicine, 7 Chung Shan South Road, Taipei, Taiwan. ${ }^{2}$ Department of Public Health, College of Public Health, China Medical University,

Taichung, Taiwan. ${ }^{3}$ Department of Integrated Diagnostics and Therapeutics, National Taiwan University Hospital and College of Medicine, Taipei, Taiwan. ${ }^{4}$ Department of Internal Medicine, Far Eastern Memorial Hospital, New Taipei, Taiwan. ${ }^{5}$ Department of Internal Medicine, Kang-Ning General Hospital,

Taipei, Taiwan. ${ }^{6}$ Department of Oncology, National Taiwan University 
Hospital and College of Medicine, Taipei, Taiwan. ${ }^{7}$ Institute of Occupational Medicine and Industrial Hygiene, National Taiwan University College of Public Health, 17 XuZhou Road, Taipei, Taiwan. ${ }^{8}$ Department of Public Health, National Taiwan University College of Public Health, Taipei, Taiwan.

${ }^{9}$ Department of Environmental and Occupational Medicine, National Taiwan University Hospital and College of Medicine, Taipei, Taiwan.

Received: 1 August 2013 Accepted: 28 November 2013

Published: 6 December 2013

\section{References}

1. Yang SK, Yun S, Kim JH, Park JY, Kim HY, Kim YH, Chang DK, Kim JS, Song IS, Park JB, et al: Epidemiology of inflammatory bowel disease in the Songpa-Kangdong district, Seoul, Korea, 1986-2005: a KASID study. Inflamm Bowel Dis 2008, 14(4):542-549.

2. Yang SK, Hong WS, Min YI, Kim HY, Yoo JY, Rhee PL, Rhee JC, Chang DK, Song IS, Jung SA, et al: Incidence and prevalence of ulcerative colitis in the Songpa-Kangdong District, Seoul, Korea, 1986-1997. J Gastroenterol Hepatol 2000, 15(9):1037-1042.

3. Yoshida Y, Murata Y: Inflammatory bowel disease in Japan: studies of epidemiology and etiopathogenesis. Med Clin North Am 1990, 74(1):67-90.

4. Chow DK, Leong RW, Tsoi KK, Ng SS, Leung WK, Wu JC, Wong WW, Chan FK, Sung Jj: Long-term follow-up of ulcerative colitis in the Chinese population. Am J Gastroenterol 2009, 104(3):647-654.

5. Ling KL, Ooi CJ, Luman W, Cheong WK, Choen FS, Ng HS: Clinical characteristics of ulcerative colitis in Singapore, a multiracial city-state. J Clin Gastroenterol 2002, 35(2):144-148.

6. Asakura K, Nishiwaki Y, Inoue N, Hibi T, Watanabe M, Takebayashi T: Prevalence of ulcerative colitis and Crohn's disease in Japan. J Gastroenterol 2009, 44(7):659-665.

7. Ouyang Q, Tandon R, Goh KL, Ooi CJ, Ogata H, Fiocchi C: The emergence of inflammatory bowel disease in the Asian Pacific region. Curr Opin Gastroenterol 2005, 21(4):408-413.

8. Ooi CJ, Fock KM, Makharia GK, Goh KL, Ling KL, Hilmi I, Lim WC, Kelvin T, Gibson PR, Gearry RB, et al: The Asia-Pacific consensus on ulcerative colitis. J Gastroenterol Hepatol 2010, 25(3):453-468.

9. Yao T, Matsui T, Hiwatashi N: Crohn's disease in Japan: diagnostic criteria and epidemiology. Dis Colon Rectum 2000, 43(10 Suppl):S85-S93.

10. Hsiao CH, Wei SC, Wong JM, Lai HS, Chang MH, Ni YH: Pediatric Crohn disease: clinical and genetic characteristics in Taiwan. J Pediatr Gastroenterol Nutr 2007, 44(3):342-346.

11. Wei SC, Ni YH, Yang HI, Su YN, Chang MC, Chang YT, Shieh MJ, Wang CY, Wong JM: A hospital-based study of clinical and genetic features of Crohn's disease. J Formos Med Assoc 2011, 110(9):600-606.

12. Wei SC, Shieh MJ, Chang MC, Chang YT, Wang CY, Wong JM: Long-term follow-up of ulcerative colitis in Taiwan. J Chin Med Assoc 2012, 75(4):151-155.

13. Chiu HF, Ho SC, Chen CC, Yang CY: Statin use and the risk of liver cancer: a population-based case-control study. Am J Gastroenterol 2011, 106(5):894-898.

14. Lai MN, Wang SM, Chen PC, Chen YY, Wang JD: Population-based case-control study of Chinese herbal products containing aristolochic acid and urinary tract cancer risk. J Natl Cancer Inst 2010, 102(3):179-186.

15. Tsan YT, Lee CH, Wang JD, Chen PC: Statins and the risk of hepatocellular carcinoma in patients with hepatitis B virus infection. J Clin Oncol 2012, 30(6):623-630

16. Prideaux L, Kamm MA, De Cruz PP, Chan FK, Ng SC: Inflammatory bowel disease in Asia: a systematic review. J Gastroenterol Hepatol 2012 27(8):1266-1280

17. Ng SC, Tang W, Ching JY, Wong M, Chow CM, Hui AJ, Wong TC, Leung VK, Tsang SW, Yu HH, et al: Incidence and phenotype of inflammatory bowel disease based on results from the Asia-pacific Crohn's and colitis epidemiology study. Gastroenterology 2013, 145(1):158-165. e152.

18. Tragnone A, Corrao G, Miglio F, Caprilli R, Lanfranchi GA: Incidence of inflammatory bowel disease in Italy: a nationwide population-based study. Gruppo Italiano per lo Studio del Colon e del Retto (GISC). Int $J$ Epidemiol 1996, 25(5):1044-1052.

19. Button LA, Roberts SE, Goldacre MJ, Akbari A, Rodgers SE, Williams JG: Hospitalized prevalence and 5-year mortality for IBD: record linkage study. World J Gastroenterol 2010, 16(4):431-438.

20. Canavan C, Abrams KR, Mayberry JF: Meta-analysis: mortality in Crohn's disease. Aliment Pharm Ther 2007, 25(8):861-870
21. Doi Y, Yokoyama T, Sakai M: [Trends in mortality from intractable diseases in Japan, 1972-2004]. [Nihon koshu eisei zasshi] Japanese. J Public Health 2007, 54(10):684-694.

22. Duricova D, Pedersen N, Elkjaer M, Gamborg M, Munkholm P, Jess T: Overall and cause-specific mortality in Crohn's disease: a meta-analysis of population-based studies. Inflamm Bowel Dis 2010, 16(2):347-353.

23. Hutfless SM, Weng X, Liu L, Allison J, Herrinton LJ: Mortality by medication use among patients with inflammatory bowel disease, 1996-2003. Gastroenterology 2007, 133(6):1779-1786

24. Jess T, Riis L, Vind I, Winther KV, Borg S, Binder V, Langholz E, Thomsen OO, Munkholm P: Changes in clinical characteristics, course, and prognosis of inflammatory bowel disease during the last 5 decades: a population-based study from Copenhagen, Denmark. Inflamm Bowel Dis 2007, 13(4):481-489.

25. Persson PG, Bernell O, Leijonmarck CE, Farahmand BY, Hellers G, Ahlbom A: Survival and cause-specific mortality in inflammatory bowel disease: a population-based cohort study. Gastroenterology 1996, 110(5):1339-1345.

26. Peyrin-Biroulet L, Loftus EV Jr, Colombel JF, Sandborn WJ: Long-term complications, extraintestinal manifestations, and mortality in adult Crohn's disease in population-based cohorts. Inflamm Bowel Dis 2011, 17(1):471-478

27. Romberg-Camps M, Kuiper E, Schouten L, Kester A, Hesselink-van de Kruijs M Limonard C, Bos R, Goedhard J, Hameeteman W, Wolters F, et al: Mortality in inflammatory bowel disease in the Netherlands 1991-2002: results of a population-based study: the IBD South-Limburg cohort. Inflamm Bowel Dis 2010, 16(8):1397-1410.

28. Selinger $\mathrm{CP}$, Leong RW: Mortality from inflammatory bowel diseases. Inflamm Bowel Dis 2012, 18(8):1566-1572.

29. Travis SP: Review article: insurance risks for patients with ulcerative colitis or Crohn's disease. Aliment Pharm Ther 1997, 11(1):51-59.

30. Uno H, Yao T, Matsui T, Sakurai T, lida M, Matsumoto T, Aoyagi K, Fuchigami T: Mortality and cause of death in Japanese patients with Crohn's disease. Dis Colon Rectum 2003, 46(10 Suppl):S15-S21.

31. Winther KV, Jess T, Langholz E, Munkholm P, Binder V: Survival and cause-specific mortality in ulcerative colitis: follow-up of a population-based cohort in Copenhagen County. Gastroenterology 2003, 125(6):1576-1582

\section{doi:10.1186/1471-230X-13-166}

Cite this article as: Wei et al: A nationwide population-based study of the inflammatory bowel diseases between 1998 and 2008 in Taiwan. BMC Gastroenterology 2013 13:166.

\section{Submit your next manuscript to BioMed Central and take full advantage of:}

- Convenient online submission

- Thorough peer review

- No space constraints or color figure charges

- Immediate publication on acceptance

- Inclusion in PubMed, CAS, Scopus and Google Scholar

- Research which is freely available for redistribution 